\title{
LIGHT METALS ALLIANCE: LIGHT METALS TECHNOLOGY 2017 SPECIAL SECTION
}

The papers in this LMT2017 Special Section were presented at the Light Metals Alliance: Light Metals Technology 2017 Symposium held during the Materials Science \& Technology 2017 (MS\&T 2017) from 10/08/2017 to 10/12/2017, Pittsburgh, PA, USA.

\section{LMT 2017 Organizer(s):}

- Diran Apelian, Worcester Polytechnic Institute.

- Kumar Sadayappan, CanmetMATERIALS.

- Frank Czerwinski, CanmetMATERIALS.

- Brajendra Mishra, Worcester Polytechnic Institute.

- Michael John Bermingham, The University of Queensland.

- Wenjiang Ding, Shanghai Jiao Tong University.

- Zhongyun Fan, Brunel University.

- Gonasagren Govender, The Council for Scientific and Industrial Research (CSIR).

- Karl Ulrich Kainer, Helmholtz-Zentrum Geesthacht.

- Andreas Kraly, LKR Leichtmetallkompetenzzentrum Ranshofen $\mathrm{GmbH}$.

- Salem Seifeddine, Jönköping University.

- Bong Sun You, Korea Institute of Materials Science.

Symposium Scope

The symposium focused on recent advances in the science and technologies associated with light metals, in particular aluminum, magnesium and titanium alloys. It presented an opportunity for researchers from academy, government labs and industry to meet and discuss cutting edge developments and to facilitate new collaborations. The major topics covered several aspects including alloy development, melt processing innovations, novel forming technologies, joining, heat treatment, recycling and sustainability, corrosion and surface modification, mechanical behavior, advanced characterization techniques, simulation and modelling, applications in automotive, aerospace, energy and bio-medical industries.

The invited LMT2017 papers published from that symposium:

1. The Role of $\mathrm{Zn}$ Additions on the Microstructure and Mechanical Properties of $\mathrm{Mg}-\mathrm{Nd}-\mathrm{Zn}$ Alloys.

2. Effect of Co and Ni Addition on the Microstructure and Mechanical Properties at Room and Elevated Temperature of an $\mathrm{Al}-7 \% \mathrm{Si}$ Alloy.

3. Complexities in the Assessment of Melt Quality.

4. Effect of Cooling Rate on the Mechanical Properties of AA365 Aluminum Alloy HeatTreated Under T4, T5, and T6 Conditions.

5. Effect of Titanium Levels on the Hot Tearing Sensitivity and Abnormal Grain Growth After T4 Heat Treatment of $\mathrm{Al}-\mathrm{Zn}-\mathrm{Mg}-\mathrm{Cu}$ Alloys. 